\title{
Forearm Oxygen Consumption and Forearm Blood Flow in Healthy Children and Adolescents Measured by Near Infrared Spectroscopy
}

\author{
G. PICHLER, B. URlesberger, P. JiRAK, H. Zotter, and W. MÜLleR \\ Department of Paediatrics, University of Graz, Austria
}

\begin{abstract}
The assessment of forearm oxygen consumption $\left(\mathrm{VO}_{2}\right)$ and forearm blood flow (FBF) by means of near infrared spectroscopy has become widespread in adults, whereas in children and adolescents no data are available. The aim of the present study was to analyze $\mathrm{VO}_{2}$ and $\mathrm{FBF}$ in healthy children and adolescents. Methods: In a prospective cohort study, 20 male and 20 female healthy children and adolescents were investigated. The measurements of $\mathrm{VO}_{2}$ and $\mathrm{FBF}$ were performed by means of near infrared spectroscopy in combination with the venous occlusion method. Results: Mean $\mathrm{VO}_{2}$ was $0.08 \pm 0.04$
\end{abstract}

$\mathrm{ml} 100 \mathrm{~g}^{-1} \mathrm{~min}^{-1}$ in male and $0.09 \pm 0.05 \mathrm{ml}^{100 \mathrm{~g}^{-1} \mathrm{~min}^{-1} \text { in fe- }}$

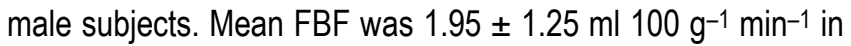

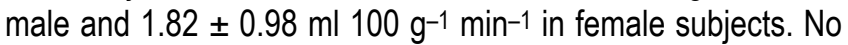
significant difference was found between male and female subjects. A significant negative correlation of $\mathrm{VO}_{2}$ and $\mathrm{FBF}$ to age was observed in both groups. Conclusion: In the present study we were able to show that $\mathrm{VO}_{2}$ and $\mathrm{FBF}$ decreased with increasing age in children and adolescents without significant differences between male and female subjects.

Key words: near infrared spectroscopy, forearm oxygen consumption, forearm blood flow, development.

Near infrared spectroscopy (NIRS) is a relatively new method, which is noninvasive and continuous and operates in real time, thus enabling in-vivo monitoring of tissue oxygenation and hemodynamics. NIRS has been applied to measure the oxygenation and hemodynamics of a variety of tissues, including muscle, brain, and connective tissue. With an adequate optode separation (more than 20 $\mathrm{mm}$ ), the skin and the subcutaneous fat constitutes less than $5 \%$ of the signal measured over a given body segment in lean subjects $[1,2]$. The NIRS signal therefore predominately reflects the microcirculation and $\mathrm{O}_{2}$ availability of tissue, which is dependent on interoptode distance, $2-6 \mathrm{~cm}$ deep [1]. Thus by positioning the optodes on the forearm, NIRS enables the measurement of the oxygenation and hemodynamics of forearm muscle.

The venous occlusion, another noninvasive method, in combination with NIRS has been validated and has become an accepted method for the assessment of forearm muscular oxygen consumption $\left(\mathrm{VO}_{2}\right)[3-5]$ and forearm blood flow (FBF) [6]. Nevertheless, most studies on muscle oxygenation and hemodynamics were performed on healthy adults and adult patients $[1,4,7]$ and on term and preterm neonates $[8,9]$. In a recent study we analyzed FBF in children and adolescents with type I diabetes and healthy children and adolescents [6].

The aim of the present study was the measurement and analysis of $V \mathrm{O}_{2}$ and $\mathrm{FBF}$ of forearm muscle in healthy children and adolescents.

\section{METHODS}

Children and adolescents aged from 6 to 18 years were studied. The subjects, who were obese, i.e., body mass index (BMI) beyond the 90th percentile, or who had taken any medicaments within the past seven days, were excluded. Male and female subjects were matched for age ( \pm 6 months). Each subject was a volunteer, and informed consent was obtained from all parents and adolescents before we started measurements. The study was approved by the local ethical committee.

NIRS measurements were carried out with the NIRO 300 (Hamamatsu Phonics, Japan). This equipment includes four laser diodes for measurements with wavelengths of $775,825,850$, and $904 \mathrm{~nm}$. The optodes were placed over the brachioradial muscle of the left forearm 4 $\mathrm{cm}$ distal of the elbow, the interoptode distance was 3.5 $\mathrm{cm}$, and the sampling rate was $2 / \mathrm{s}$. A differential path length factor of 4.16 was used [10]. NIRS enables the noninvasive continuous measurement of changes in the concentration of oxygenated hemoglobin $\left(\Delta \mathrm{cHbO}_{2}\right)$, deoxygenated hemoglobin $(\Delta \mathrm{cHb})$, and cytochrome oxidase $(\Delta \mathrm{cCytO})$. NIRS parameters were measured in $\mu \mathrm{M}$ units.

$V \mathrm{O}_{2}$ was calculated by evaluating the rate of the increase of $\Delta \mathrm{cHb}$ converted into $\mathrm{ml} \mathrm{O}_{2} / 100 \mathrm{~g} / \mathrm{min}$. Mean forearm density was estimated at $1.04 \mathrm{~kg} l^{-1}$ [11].

FBF was calculated from the linear increase of cHbtot during venous occlusion measured by NIRS, taking into account the hemoglobin value of each subject. Further-

Received on Jan 29, 2006; accepted on May 10, 2006; released online on May 20, 2006; doi:10.2170/physiolsci.RP001906 Correspondence should be addressed to: Gerhard Pichler, Department of Paediatrics, University of Graz, Auenbruggerplatz 30,8036 Graz, Austria. Fax: +43 316385 2678, E-mail: Gerhard.Pichler2@klinikum-graz.at 
more, the molecular weight $(64.458 \mathrm{~g} / \mathrm{mol})$ and the molecular ratio between hemoglobin and oxygen (1:4) were taken into account. FBF was expressed in $\mathrm{ml} / 100 \mathrm{~g}$ muscle/ min.

For venous occlusion a pneumatic cuff was placed around the arm above the elbow. The subjects were sitting in a comfortable chair. The left arm was placed at the level of the right atrium. Heart rate and peripheral arterial oxygen saturation were measured by pulse oximetry, whereby the sensor was placed on the third finger of the left hand.

After the placements of the optodes, pneumatic cuff, and oximetry, there was a 10 -min rest period. The measurement of blood pressure was then performed. After a rest period of $1 \mathrm{~min}$, again the pneumatic cuff was inflated within $0.5-1 \mathrm{~s}$ to a pressure, which was below the diastolic arterial pressure and above the venous pressure. The cuff was maintained inflated for $20 \mathrm{~s}$. This procedure was repeated three times with a rest period of $40 \mathrm{~s}$ between the inflations. To define $V \mathrm{O}_{2}$ and FBF in each subject, we calculated the mean of the three measurements. Hemoglobin concentrations of blood were analyzed from a blood sample.

For a comparison of male and female subjects, the data of $V \mathrm{O}_{2}$ and $\mathrm{FBF}$ at rest were compared by the unpaired Student's $t$-test. For comparison of the three measurements of $V \mathrm{O}_{2}$ and FBF at rest, the paired Student's $t$-test was used, respectively. $V \mathrm{O}_{2}$ and $\mathrm{FBF}$ were correlated to age, arm circumference, standard deviation score of BMI [12], hemoglobin concentration, heart rate, oxygen saturation, and arterial blood pressure by linear and polynomial regression analysis. The data are represented as mean \pm $\mathrm{SD}$, if not stated otherwise. The level of statistical significance was set at $p<0.05$. All statistical analyses of recorded data were performed with Statview 4.5 Software.

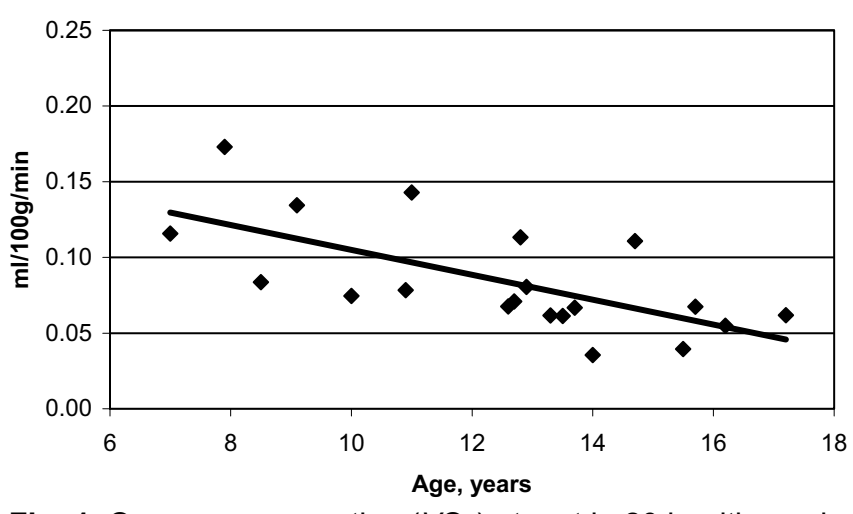

Fig. 1. Oxygen consumption $\left(\mathrm{VO}_{2}\right)$ at rest in 20 healthy male children and adolescents. Significant correlation of age to $\mathrm{VO}_{2} . \mathrm{Y}=0.185-0.008^{*} X ; r=0.66, p=0.001$.

\section{RESULTS}

A total number of 40 children and adolescents, 20 male and 20 female subjects, were measured (Table 1). $\mathrm{VO}_{2}$ and FBF were similar in male and female subjects. Furthermore, no significant differences could be observed in any of the analyzed parameters between the subjects (Table 1).

The three consecutive measurements of $V \mathrm{O}_{2}(0.08 \pm$ $0.05 ; 0.09 \pm 0.04 ; 0.09 \pm 0.05 \mathrm{ml} 100 \mathrm{~g} \mathrm{muscle}^{-1} \mathrm{~min}^{-1}$; n.s.) and FBF $(1.86 \pm 1.05 ; 1.91 \pm 1.14 ; 1.90 \pm 0.95 \mathrm{ml}$ $100 \mathrm{~g} \mathrm{muscle}^{-1} \mathrm{~min}^{-1}$; n.s.) within subjects showed high reproducibility.

$V \mathrm{O}_{2}$ was significantly correlated to age, whereby $V \mathrm{O}_{2}$ decreased with increasing age (Figs. 1 and 2). FBF also decreased with increasing age (Figs. 3 and 4). $V \mathrm{O}_{2}$ and FBF did not correlate to any of the other analyzed variables, i.e., arm circumference, standard deviation score of BMI, hemoglobin concentration, heart rate, oxygen saturation, and arterial blood pressure (n.s.).

Table 1. Twenty healthy male and 20 healthy female children and adolescents.

\begin{tabular}{|c|c|c|c|}
\hline & \multicolumn{2}{|c|}{ Mean \pm SD } & \\
\hline & Male, $n=20$ & Female, $n=20$ & \\
\hline $\mathrm{VO}_{2}, \mathrm{ml} 100 \mathrm{~g}^{-1} \mathrm{~min}^{-1}$ & $0.08 \pm 0.04$ & $0.09 \pm 0.05$ & n.s. \\
\hline $\mathrm{FBF}, \mathrm{ml} 100 \mathrm{~g}^{-1} \mathrm{~min}^{-1}$ & $1.95 \pm 1.25$ & $1.82 \pm 0.98$ & n.s. \\
\hline Age, years & $12.5 \pm 2.9$ & $12.8 \pm 3.1$ & n.s. \\
\hline Body weight, kg & $45.1 \pm 14.7$ & $46.2 \pm 12.6$ & n.s. \\
\hline Height, cm & $152.5 \pm 16.5$ & $154.3 \pm 16.5$ & n.s. \\
\hline Body mass index (BMI) & $18.8 \pm 2.9$ & $19.1 \pm 2.8$ & n.s. \\
\hline Standard deviation score (BMI) & $0.01 \pm 0.85$ & $-0.01 \pm 1.07$ & n.s. \\
\hline Arm circumference, $\mathrm{cm}$ & $23.2 \pm 3.7$ & $23.1 \pm 2.8$ & n.s. \\
\hline Hemoglobin concentration, g/dl & $13.3 \pm 1.7$ & $13.3 \pm 1.4$ & n.s. \\
\hline Heart rate/min & $87 \pm 12$ & $87 \pm 14$ & n.s. \\
\hline Oxygen saturation, $\%$ & $98 \pm 0.5$ & $98 \pm 0.2$ & n.s. \\
\hline Systolic blood pressure, $\mathrm{mmHg}$ & $99 \pm 12$ & $97 \pm 9$ & n.s. \\
\hline Diastolic blood pressure, $\mathrm{mmHg}$ & $58 \pm 10$ & $56 \pm 7$ & n.s. \\
\hline
\end{tabular}




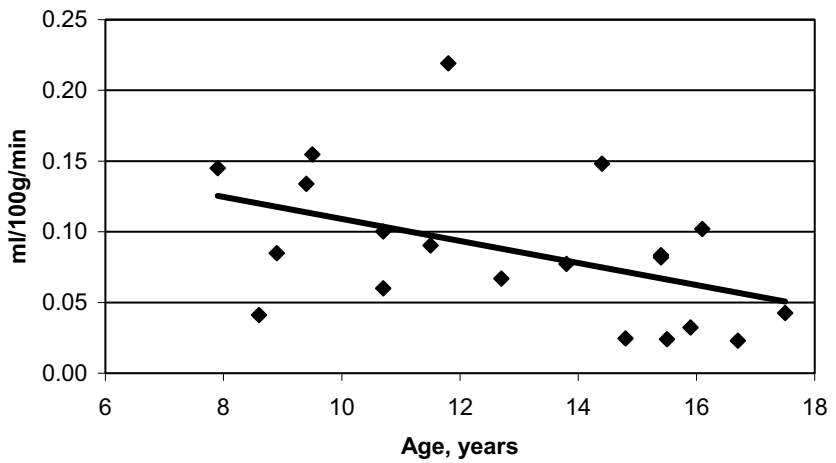

Fig. 2. Oxygen consumption $\left(\mathrm{VO}_{2}\right)$ at rest in 20 healthy female children and adolescents. Significant correlation of age to $\mathrm{VO}_{2} . \mathrm{Y}=0.184-0.008{ }^{*} \mathrm{X} ; r=0.45, p=0.048$.

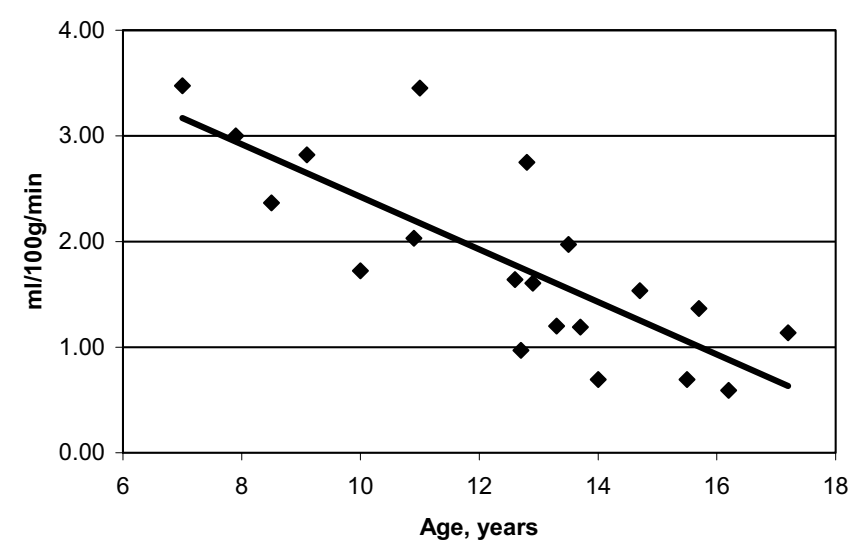

Fig. 3. Forearm blood flow (FBF) at rest in 20 healthy male children and adolescents. Significant correlation of age to FBF. $Y=5.24-0.27^{*} X ; r=0.80, p<0.001$.

With increasing age, the arm circumference also increased $(r=0.52, p=0.0006)$. The other parameters were independent of age (n.s.). No change of $\mathrm{SaO}_{2}$ or heart rate was observed during venous occlusion.

\section{DISCUSSION}

The present study was the first that showed the age dependency of $V \mathrm{O}_{2}$ in healthy children and adolescents with no difference between male and female subjects. $V \mathrm{O}_{2}$ decreased with increasing age. FBF decreased with increasing age, too, as we have recently reported [6].

In regard to the positioning and penetration depth of NIRS, which is about half of the interoptode distance [1, 11], the measurements of a particular tissue region, namely, the brachioradial muscle, were performed in all subjects. $\mathrm{VO}_{2}$ and $\mathrm{FBF}$ of this particular region were independent of arm circumference, which is a measure of the whole size of the arm.

Recent studies demonstrated that adipose tissue thickness (from 1 to $10 \mathrm{~mm}$ ) correlates with $\mathrm{FBF}$ and $V \mathrm{O}_{2}$, whereby $\mathrm{VO}_{2}$ decreases and FBF increases with increasing adipose tissue thickness [11]. In the present study, adi-

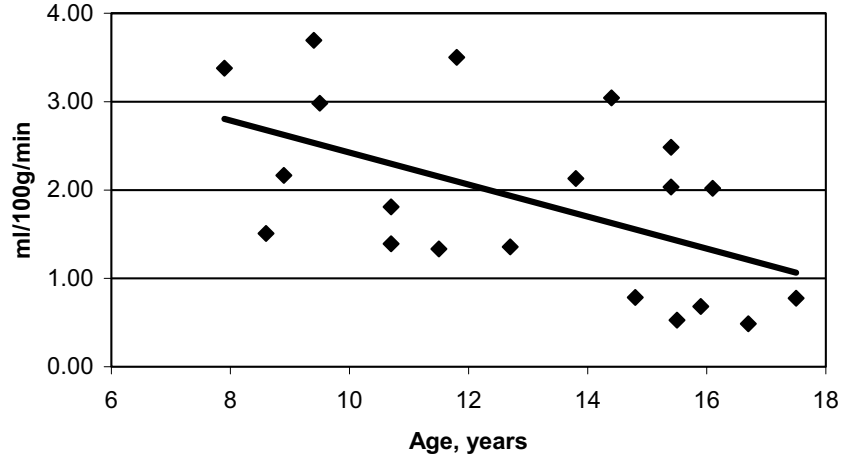

Fig. 4. Forearm blood flow (FBF) at rest in 20 healthy female children and adolescents, Significant correlation of age to FBF. $Y=3.93-0.16{ }^{*} X ; r=0.51, p=0.026$.

pose tissue thickness was not measured; therefore a possible influence on results cannot be clearly ruled out. Nevertheless, we found a decrease of FBF with increasing age that suggests a negligible influence of the increasing adipose tissue thickness with increasing age on the changes of FBF and $V \mathrm{O}_{2}$. The increase of the adipose tissue thickness in European children aged from 6 to 10 years was described to be about 0.5 to $1.5 \mathrm{~mm}$ [13]. Furthermore, since obese subjects were excluded in the present study, the influence of the overlying skin and the subcutaneous fat can be assumed to be less than $5 \%[1,2]$. This is supported by the missing correlation of $V \mathrm{O}_{2}$ and $\mathrm{FBF}$ to $\mathrm{BMI}$ and the standard deviation score of BMI.

In the present study, no influence of heart rate, blood pressure, or oxygen saturation has been observed. According to literature, muscular perfusion and as a consequence oxygen supply are mainly influenced by local vasoactive compounds, i.e., acetylcholine, NO, and adenosine [14].

The comparison of the present values of $V \mathrm{O}_{2}$ and FBF to studies in adults is difficult. $V \mathrm{O}_{2}$ in adult varies from 0.05 to $0.23 \mathrm{ml} 100 \mathrm{~g}_{\text {muscle }}^{-1} \mathrm{~min}^{-1}$ [15]. The variety of FBF is similar $[1,4,5]$. The reason for this variety might be the factors used in calculation. First the differential path length factor varies from 2.6 to 4.57 [2, 4]. Second, the factor for muscle density varies from $1.04 \mathrm{~kg} \mathrm{l}^{-1}$ [4, 15] to $1.14 \mathrm{~kg} \mathrm{l}^{l^{-1}}$ [16]. Furthermore, we find a different positioning of optodes in comparing the studies. Since NIRS measures local $V \mathrm{O}_{2}$ and FBF, which may be different in different muscle groups, the place where the optodes are positioned have an effect on the obtained values [5]. In the present study, the same factors were used in all subjects, and the optodes were positioned in the same way that makes the obtained data comparable.

In adults a great variability between subjects and high reproducibility within them have been reported [4]. Similar observations could be made in the present study with high reproducibility within subjects. The variability between subjects, however, was mainly age related, which 


\section{G. PICHLER et al.}

may be due to the ongoing development of the muscle during childhood.

Little is known about the development of the skeletal muscle system during childhood and adolescence. Causes of the observed present age-dependent changes might be changes in muscle cross-sectional area and metabolism during growth that is still discussed as being controversial [17-21]. A comparison of muscular fatigue of boys and of adult men suggests that more fatigable Type 2 fibers are involved in men, resulting in greater lactic acid and ion accumulation during fatigue [18]. Children rely less on glycolysis than adults do during high-intensity exercise, leading to a lower production of lactate during intense cycling [19].

With the present data, the reason for the age dependency of $V \mathrm{O}_{2}$ and $\mathrm{FBF}$ cannot be ruled out, but the findings of the age dependency of $V \mathrm{O}_{2}$ and $\mathrm{FBF}$ are important. In further studies the present observations of $\mathrm{VO}_{2}$ and $\mathrm{FBF}$ in children and adolescents must be taken into account.

\section{REFERENCES}

1. Boushel R, Langberg H, Olesen K, Nowak M, Simonsen L, Bulow J, Kjaer M: Regional blood flow during exercise in humans measured by near-infrared spectroscopy and indocyanine green. J Appl Physiol. 2000;89:1868-78.

2. Mancini DM, Bolinger L, Li H, Kendrick K, Chance B, Wilson JR. Validation of near-infrared spectroscopy in humans. J Appl Physiol. 1994;77:2740-7.

3. De Blasi RA, Almenraeder N, Aurisiccho P, Ferrari M. Comparison of two methods of measuring forearm oxygen consumption (VO2) by near infrared spectroscopy. J Biomed Opt. 1997;2:171-5.

4. Van Beekvelt MCP, Colier WNJM, Van Engelen BGM, Hopman MTE, Wevers RA, Oeseburg B. Validation of measurement protocols to assess oxygen consumption and blood flow in the human forearm by near infrared spectroscopy. SPIE. 1997;3294:133-44.

5. Van Beekvelt MCP, Colier WNJM., Wevers RA, Van Engelen BGM. Performance of near infrared spectroscopy in measuring local $\mathrm{O} 2$ consumption and blood flow in skeletal muscle. J Appl Physiol. 2001;90:511-9.
6. Pichler G, Urlesberger B, Jirak P, Zotter H, Reiterer E, Muller W, Borkenstein M. Reduced forearm blood flow in children and adolescents with type 1 diabetes (measured by near-infrared spectroscopy). Diabetes Care. 2004;27:1942-1946.

7. Ferrari M, Binzoni T, Quaresima V. Oxidative metabolisme in muscle. Phil Trans R Soc Lond B. 1997;352:677-83.

8. Hassan IAA, Wickramasinghe YA, Spencer SA. Effect of limb cooling on peripheral and global oxygen consumption in neonates. Arch Dis Child Fetal Neonatal Ed. 2003;88:F139-42.

9. Wardle SP, Weindling AM. Peripheral oxygenation in preterm infants. Cin Perinatol. 1999;26:947-66.

10. Duncan A, Meek JH., Clemence M, Elwell CE, Tyszczuk L, Cope M, Delpy DT. Optical path length measurements on adult head, calf and forearm and head of the newborn infant using phase resolved optical spectroscopy. Phys Med Biol. 1995;40:295-304.

11. Van Beekvelt MCP, Borghuis MS, Van Engelen, ZGM, Wevers RA, Colier WNJM. Adipose tissue thickness affects in vivo quantitative near-IR spectroscopy in human skeletal muscle. Clin Sci. 2001:101:21-8.

12. Cole TJ. The LMS method for constructing normalized growth standards. Eur $\mathrm{J}$ Clin Nutr. 1990;44:45-60.

13. Meredith HV. Childhood studies on thickness of skin and subcutaneous adipose tissue at arm back: a review. Hum Biol. 1985;57:525-62.

14. Saltin B, Radegran G, Koskolou MD, Roach RC. Skeletal muscle blood flow in humans and its regulation during exercise. Acta Physiol Scand. 1998;162:42136 .

15. Van Beekvelt MCP, Van Engelen BGM., Wevers RA, Colier WNJM. In vivo quantitative near infrared spectroscopy in skeletal muscle during incremental isometric handgrip exercise. Clin Physiol Funci Imaging. 2000;22:210-7.

16. Edwards AD, Richardson C, Van der Zee P, Elwell C, Wyatt JS, Cope M, Delpy DT, Reynolds EO. Measurement of hemoglobin flow and blood flow by nearinfrared spectroscopy. J Appl Physiol. 1993;75:1884-9.

17. Bell RD, MacDougall JD, Billeter, R, Howald H. Muscle fiber types and morphometric analysis of skeletal muscle in six year old children. Med Sci Sports Exerc. 1980;12:28-31.

18. Halin R, Germain P, Bercier S, Kapitaniak B, Buttelli O. Neuromuscular response of young boys versus men during sustained maximal contraction. Med Sci Sports Exerc. 2003;35:1042-8.

19. Inbar O, Bar-Or O. Anaerobic characteristics in male children and adolescents. Med Sci Sports Exerc. 1986;18:264-9.

20. Lexell J, Sjostrom M, Nordlund AS, Taylor CC. Growth and development of human muscle: a quantitative morphological study of whole vastus lateralis from childhood to adult age. Muscle Nerve. 1992;15:404-9.

21. Oertel G. Morphometric analysis of normal skeletal muscles in infancy, childhood and adolescence. Ann autopsy study. J Neurol Sci. 1988;88:303-13. 